\title{
Improving the Quality of the Office Administration Programme at the Fiji National University
}

\author{
Lavenia Lawakele, Makereta Mua \\ Fiji National University, Fiji
}

\begin{abstract}
The Fiji National University ( $F N U)$ and prior to its establishment, the Fiji Institute of Technology (FIT), is a major provider of office administrators and secretaries in both the private and public sectors. Over time, technological and economic changes have impacted on the type and quality of personnel required by government and employers in the various sections of the private sector. This paper will discuss the quality and relevance of the office administration programs and courses implemented by the Fiji Institute of Technology/Fiji National University and assess the compatibility of these programs with the various needs and demands of employers. Feedback on quality of lectures, tutorial support, access to course materials and program related information and FIT/FNU support of student work attachments will also be discussed. The paper will identify areas where consultation and collaboration between FNU, employers and ex-students can occur to provide job opportunities and knowledge, skills and practical training for FNU students and graduates alike.
\end{abstract}

\section{Introduction}

Ever since its inception in 1963, Fiji Institute of Technology (FIT) and later, Fiji National University (FNU) was established to provide technical and vocational education aimed at training students to meet the human resource needs of Fiji. The core office administration courses taught at Fiji Institute of Technology and Fiji National University were practical stenography, typing, shorthand, word processing, spreadsheet applications, office support skills, customer care relations and filing and records management. The office administration programme was designed to develop students' skills and competence in secretarial work and general office administrative duties. The courses are designed to help students achieve a high level of accuracy in preparing and handling documents and ensuring highest levels of confidentiality in the workplace and competency with office computer systems.

One of the key questions that this paper will address is: Are the quality and relevance of programs and courses implemented by FIT and FNU matching the various needs and demands of employers? At a time when other training institutions are competitively operating, with government downsizing for a leaner and more efficient civil service, the above question will be examined for appropriate and relevant answers and solutions where they are needed.

\section{Objective of the Study}

This survey is being undertaken to obtain relevant information on the current status of the programme offered by the Department of Office Administration, that is:

a) Quality of content and delivery of service;

b) Relevance of output to the job market in both the public and private sectors; and

c) Appropriate improvement needed regarding content, technological upgrade and professional support in the way of methodology and expertise.

Understandably the findings should help the FNU to consultatively and collaboratively improve the services it provides. Firstly to its students with improved programs and training that are contextually relevant. Secondly, to its "partners" in the job market, with workers with the relevant qualification, skills and enthusiasm that will impact positively on national productivity and regional trade connections. The level and quality of consultation and collaboration among all partners should ensure regular upgrading of content, technology, methodology and expertise that will positively boost growth and development over time. 
This survey has added importance due to the fact that the Department of Office Administration has not undertaken any real significant survey of its programme in its entirety - internally within the campuses and contextually with the employers in the various sectors.

\section{Methodology}

It was possible to obtain information from thirty three ex-students. We also interviewed five employers (HR Managers) located in the Western Division, to get their feedback on FIT/FNU graduates who were employed as their Executive Secretaries, Personal Assistants and Office Administrators. All the students and the five employers asked that their identities remain anonymous.

A cluster sampling was used, due to financial constraints and the collecting of questionnaires. A total of 100 questionnaires were sent out, with 33 completed and returned.

\section{Analysis of Findings}

Under the following section an attempt will be made to assess the responses of the ex-students and those from the five Human Resources Managers (HRMs).

Our findings from thirty three questionnaires completed by ex-FIT/FNU students reported the following:

Regarding the relevance of the course to employment $30 \%$ awarded 5 (excellent) and 70\% awarded 4 (very good or of high standard). On positive impact of qualification for getting jobs 33\% awarded 5 and $67 \%$ awarded 4 . All the ex-student confirmed that the courses were extremely relevant and greatly enhanced their chances for employment. Employers' support for part-time study-27\% of students awarded a 5 and $73 \%$ awarded a 4 . In terms of quality of lectures, content and presentation 97\% awarded a 4 and 3\% awarded a 5. Quality of tutorialsorganisation and participation $12 \%$ awarded a 3 (average/acceptable with room for improvement), $85 \%$ awarded a 4 and $3 \%$ awarded 5 .

Interestingly enough the support for part-time study by employers was greatly appreciated and rated highly by all the ex-students. Just as highly rated was the quality of the on-campus lectures (content and presentation) supported by well organized participatory/interactive tutorials. This duality between programme delivery and employer support is vitally important and needs to be approached consultatively and collaboratively by the FNU and employers to ensure that programmes and technological support are regularly updated for relevance and quality.

Regarding the quality of FIT/FNU support for student work and attachment 27\% awarded a 3; $70 \%$ awarded a 4 and only $3 \%$ awarded a 5 . While FIT/FNU support for work attachment and related practical spells may be termed above average, the $27 \%$ borderline should be a matter of concern. Ideally the aim should be to reduce this quota and improve attachment support further. This is basically a consultative and collaborative matter that has to be firmly established with progressive improvement over time. Simply put, when properly implemented it is a partnership for success for all involved.

Access to course material/references at library and resource centers - 9\% awarded 3; 52\% 4 and 39\% 5 . Course material and the relevant range of supportive references are important - they help to clarify issues discussed at lectures and tutorials and allow deeper research into areas of interest and job specialization. This warrants something better than a satisfactory provision of resources highlighted by the returns. FNU has to upgrade and update content, course material, teaching and all related services to match current needs as well as those that can be consultatively forecasted with employers.

Regarding online/internet access to course/program related information: $6 \%$ scored 1 (very low standard); $24 \% 2$ (low standard and needs urgent attention); $46 \% 3 ; 24 \%$, no-one awarded a 5. The above reveals the need for improvement. While basic texts and hard copy references are still important, FNU must take advantage of available technology to boost the students' opportunities and options for accessing information related to their programme focus and employment opportunities. Questions that come to hand or details urgently required can be accessed via the internet and related technological communication channels. Maintaining and updating records for ease of processing and access can be boosted greatly. Vitally important in this area is the proper training of students in typing/keyboarding skills and basic computer operation regarding the accessing of information locally, regionally and internationally. Government has recently encouraged with financial support the setting up of computers in secondary schools but most do not have qualified computer teachers to administer a properly co-ordinated programme involving both keyboarding and computer skills. We have here a situation where government needs to bring the Ministry of Education and FNU together to collaboratively discuss the issue and plot the best way forward.

With regards to quality of ex-students association support, $24 \%$ awarded a $1 ; 40 \% 2,30 \% 3,6 \% 4$. We 
firmly believe that ex-students' regular contact and exchange of experiences is important as a way of updating each other on progress and opportunities for improvement. Then there is also the social aspect of ex-studentship and the opportunities for development via sports and social gatherings for companionship and, vitally important, for supporting charitable activities in their various locations. This means having a national association with affiliates at the various centres, for example, Ba/Tavua, Lautoka/Nadi, Suva and others. Options should be based on centrality, accessibility and functionality - what will work best.

Regarding quality of lecture and tutorial venues and facilities, 3\% chose 2, 64\% chose 3,33\% chose 4 . This refers more to sub-centers and other locations where short term lectures and tutorials are conducted for specific purposes. This should be looked into so that better arrangements with minimal costs can be firmed out for future supportive activities out in the field. An option is to seek the support of employers within the locality - some consultation and collaboration that will boost performance and relationships that are good for all concerned.

Provision of recreational programs and facilities: $79 \%$ awarded a $3 ; 21 \%$ awarded a 4 . This will involve some on the ground survey by the FNU to see how it can improve and increase the number and quality of its facilities and at the same time examine possible collaboration with local clubs and sporting organizations about hiring their facilities at a reasonable price if not for free. When properly formulated and executed Ex-students' Associations can have a positive input in this area through fundraising for facility improvement and assisting with the development of programs. This is another area where consultation and collaboration is important.

Space on campuses - seating. $27 \%$ awarded a 3; $73 \%$ 4. Quality of student accommodation and campus service: $18 \%$ awarded a 2; $52 \% 3$ and $30 \% 4$. While campus space and seating for relaxation and talanoa (chatting) have been rated well, it is still advisable to contextually examine existing facilities developmentally and to address needs rather than wants. The ranking of accommodation and campus service was executed by students from various home backgrounds. It would be best to also survey the current situation and work on improvement - urgent ones immediately and others over time in order of priority.

On how long it would take to find a job after graduation: 9\% 1-6 months, 36\% less than 1 month, $55 \%$ stayed on from practical. Initially one would be satisfied with the surety of and the short time span needed to find employment indicated above. Realistically one would need to have a contextually updated profile of employment opportunities over the next 5 years with some forecast for the following 5 years - 10 years all told. We see the following as being important indicators: the various employment activities/sectors and their proposed development; current and forecasted job opportunities; knowledge, skills and practical training relevant to the available and proposed jobs. Very important in all of these are the appropriate consultation and collaboration within and among all partners. We need some surety that we are heading in the right direction.

Students were asked to fill out items and topics that should be included in office administration units and their relevance. The following items raised by the ex-students deserve examination nationwide, involving consultation with employers in order to confirm needs that are lacking in the current crop of graduates and the relevant upgrading of programs and units to satisfy those needs:

Students commented that typing skills have declined and need to be improved so that secretarial tasks are more effectively and efficiently accomplished. Similarly, computer skills need to be improved in order to satisfy the broad demands that can be placed on secretaries and office administrators, more specifically, powerpoint presentations, electronic filing, Microsoft Excel and Outlook. Amoor [1] asserts that many organisations today demand for secretaries who are very knowledgeable and versatile in the use of modern office technology and information systems.

Students asked that a management course be included that provides information and skills in managing an office or an organization. Customer service refresher courses on preparation and organization before, during and after meetings and skills in recording minutes. OHS policies and management appropriate in the differing working environments. Multi-skilling with secretarial skills as base.

Students also said that a good command of English both spoken and written was needed for effective communication in a variety of situations. Included in this are etiquette, diplomacy and tact and others that may be highlighted in FNU-employer consultations. Angela Birch, owner of Sandalwood Lodge in Nadi, emphasised in her presentation to the Office Administration students in Nadi the importance of having good oral communication skills, having basic accounting knowledge and being able to use excel proficiently. Ms Birch also stressed that employees had to dress in a presentable way, with personal hygiene playing an important part in their everyday lives. She also encouraged students to be honest in the workplace and to use common sense (Birch 2015, pers.comm.). 
Students also commented on general personal characteristics and skills such as patience and listening before speaking; stress management; acceptable personal appearance; appropriate communication skills and diplomacy when dealing with people of different backgrounds.

During a guest lecture at the Fiji National University in Nadi, Ian Thomas, a training consultant in the tourism industry in Fiji mentioned how important good etiquette is in the workplace with good manners and good personal grooming being at the top of the list. Thomas mentioned that in his thirty three years of work at the hotel industry he had observed a general tardiness amongst some hotel employees including a lack of personal hygiene and grooming with some employees having love bites and scaly skin $\left(\right.$ kanikani $\left.^{1}\right)$. He argued that tardiness was bad for the company image and an embarrassment to work colleagues and disrespectful to guests who were paying for good professional service (Thomas 2012, pers.comm).

Ian Thomas argued that technology have somewhat partly influenced employee behavior. A lot of employees spend time alone in front of computers, watching TV, playing video games, on mobile phones where there is a tendency to depend less on interacting with other people on a face-to-face basis. Thomas stated that the art of conversation and social skills and etiquette is fading and that solitude can cause employees to be less polite and civil towards each other and does not augur well for persons pursuing a career in the hospitality industry, as kindness and respect for others lie at the core of hospitality.

There was a suggestion to make changes and teach subjects relevant to the industry. One student commented that shorthand was no longer relevant to her as she was required to use a dictaphone at work. Owizy (n.d.) reported that many students in Nigeria felt that shorthand was given a 'monarch' position among other courses and that it was outdated and other courses such as data processing and word processing should be prioritized as it was more relevant to this day and age.

Shorthand as a compulsory course is reaching the stage of being completely removed from the Fiji National University's Office Administration Programme. Reasons ranging from being outdated, the availability of new and more efficient technological methods and the loss of interest from the students are definitely pushing aside what little remains of the course. We argue that the general lack of good command of the English language has played a key role in hindering students' progress in achieving

${ }^{1}$ Kanikani is scaling skin caused by excessive kava drinking competency in shorthand. We are also of the view that texting have had a negative impact on students ability to write proper English and their grammar skills have somewhat deteriorated.

Shorthand courses should remain and made more attractive for the learners. The skill can provide useful support outside of the office at rural gatherings, meetings outside of the computer facilities, group discussions where major issues/decisions are noted for proper updating later in the day on the computer system available. One has to be contextual and honest. There is nothing worse than taking on something new when you have not mastered the present requirement. Just as risky is to put in place a computer programme when you do not have properly trained teachers with all the basic support. A poor reader struggles with learning and a computer student is no better off without the proper training.

Should there be more marketing of Office Administration in the industry? There were a few straight-out "no" with one suggesting that there were enough secretaries around. Many more agreed there was a need for marketing and publicity for reasons such as increasing the number of skilled secretaries, personal assistants (PA) and office administrators (OA); a starting block for movement to other fields; useful skill based courses; there will always be need for OAs; need more skilled people in the workplace; refresher courses for those in need and to cater for change in technology. We hold the view that all the comments must be examined in context. After the appropriate research and consultations with employers and the various Heads of Sections, decisions can then be made to make the necessary changes for improvement. On the ground facts or contextually obtained data/information is always a safe approach for decision making.

Students were asked whether students clubs should be formed and what useful purposes they serve. All were in favor of establishing clubs with various reasons that can be categorized as follows:

a. Upgrading of study facilities, presumably through students' association projects.

b. Socializing through which friendships are formed and exchange of experiences, expertise, interest and hobbies are channeled and developed.

c. Development of organizational skills through organizing club activities internally and competitively with other student clubs.

d. Staff and student inter-action outside of official lecture programs and activities.

e. Allows students to participate in healthy activities and not delve in "bad stuff".

f. Strengthening current interests and skills and developing new ones. 
g. Broadening one's skills base and experience via sports, intercultural activities and networking with other students.

h. Encouraging participation in sports as a means of maintaining physical fitness and adequate opportunities for social development.

We would like to add the importance of the involvement/participation of ex-students, not to be in control but to encourage and boost student involvement and in the process help to develop and consolidate all of the above listed items.

Five employers (HRMs) were interviewed. When asked whether graduates had the required knowledge and skills for the job 1 awarded a 3 (average/unacceptable with room for improvement); 4 awarded a 4 (very good or of a high standard). On whether graduates displayed good work ethics 1 awarded a 3; 4 employers awarded a 4. On whether graduates were punctual and used time efficiently 1 awarded a 3 and 4 employers a 4 . On whether graduates displayed good manners and respect for employers and fellow employees, 5 employers rated their graduates with a 4 . Good manners and respect for employers and employees have been rated highly by all. This sets a good foundation on which to build and strengthen team work interactively throughout the ranks.

When asked whether graduates displayed initiative, 3 awarded 3 while 2 awarded a 4 . This rating suggests the need for improvement from an average majority upwards to more efficient display of initiative and responsibility. Comments from employers on what they see as essential characteristics in their respective locations/industry will help FNU to make the necessary adjustments to its programme to help current and future students to prepare better for employment.

Employers were asked whether graduates accepted criticism and responded positively in an effort to improve. 2 employers awarded 3 and 3 awarded a 4. All employers said graduates were good team players. Reacting positively to criticism and good team work are important in any organization and should be encouraged throughout FNU. Students who spend time to assess their weaknesses and take the initiative to find solutions or to seek assistance have developed a positive foundation on which to develop and overcome challenges in the workplace.

When asked whether FIT/FNU lecturers regularly followed up on their former students' progress, 4 employers awarded a 2 with one employer awarding a 4. This is definitely an area needing improvement. Regular contact with ex-students to update FNU on experiences and the demands of the various employment sectors is essential. Having them to provide guest lectures on specific issues/activities and to be members of academic/professional committees is the way to go - programmes are given relevance and students will be better prepared to face the demands of employment. However, another area where students' progress should be monitored is in the workplace itself. Amoor [2] makes an important point in that interactions with the students revealed that quite often, secretarial students were not properly placed in offices where they would acquire the practical skills and competence in modern office technology and information systems. Some of them, who were assumed properly placed, were not strictly supervised by the organisations' supervisors and this reduced students' commitment.

All employers agreed on the need for more marketing of the Office Administration Programme. For FNU, consultation will provide them with the needs of the various employment sectors and how to make programme adjustments to help prepare students better for a good "employment fit".

On how FIT/FNU graduates performed compared to other employees all employers said that FIT/FNU graduates have performed very well compared to those from other institutions. This is something to be pleased about but not to be complacent about. Given the changes and demands of the "new" employment sectors it is vitally important to have up to date information of the working environment and characteristics. This warrants efficient linkages with employers so that changes are taken into account when revising FNU programmes over time to allow for a positive match between employees qualification and training and job market requirements. It is vitally important to have FNU trained employees to continue to perform better than other employees.

\section{Findings}

When reflecting on the submissions from the exstudents and employers (HRMs) the following interesting features appear:

The students rated course relevance and quality and its impact on securing employment very highly. The HRMs rated the graduates' knowledge, skills, work ethics, manners and respect for employers and fellow employees to be generally very good, indicating a good match between course content and delivery with the demands of the workplace.

While ex-students were generally very satisfied with work attachment support provided by the FIT/FNU, the employers were not as satisfied with the rate/quality of workplace follow-up displayed by them. A golden opportunity for regular updating with contextual experience was missed out by the 
FIT/FNU. This is another area requiring regular consultation, collaboration and visitation.

A close examination of the ex-students "average" assessment of access to course material, references and programme related items via FNU libraries, resource centres and available internet services warrants serious examination and upgrading with ongoing re-assessment. Understandably there will be financial implications warranting a needs assessment to direct the overall development programme.

The importance of marketing the Office Administration Programme was rated very highly by both groups with student responses highlighting various reasons that warrant the strengthening of the units of study with the necessary publicity. We see this as being important. When the public in general know the quality of the units of study under the various programs and their relevance and importance for securing employment a win-win situation is created: interest from students vying for training is boosted with a wider base of suitable candidates; FNU understandably will maintain the best of facilities with qualified staff to provide the appropriate services and standards; both the Public and Private Sectors become the recipient of better quality employees with the ability to provide quality services. And most certainly quality goods and services benefit the public who are the recipients and whose payment boosts the earnings of the providers. This may appear idealistic but we believe it is something to aim for in order to provide something better than what is currently available.

On a comparative basis the five employers have rated FIT/FNU trained employees higher than others. This is not an assessment to relax over but a good platform on which to build. One approach is to find out "in what ways the FNU graduates are better" "and to find out where they are lacking or can improve on". The two sets of data should help strengthen both the theoretical and practical aspects of the current FNU programme. We live in a changing world and FNU must constantly note the changes in the job environment generally to ensure that new developments or changes are accommodated in their training programme.

\section{Conclusion}

The establishment and development of consultative and collaborative networking within the FNU and between the FNU and the various components of the public and private sectors are important. All concerned should regularly share their findings and views in order to better appreciate the best courses and appropriate training programmes that the FNU needs to have in place to ensure that its graduates are well prepared to undertake their responsibilities in their respective jobs in both the public and private sectors. Positive networking can be established and grown over time in several ways, some of which are to create informal exchanges between employers and training institutions when issues requiring some attention/solution appear in the workplace or training institution. Sharing ideas and experiences could lead to some positive change.

The establishment of Executive Boards responsible for the various FNU training programmes with public and private sector membership to allow regular consultation on problems as well as new developments warranting the views of all involved plus those with relevant expertise- together as a team to activate relevant changes for improvement.

With regards to the students claim that etiquette, diplomacy and tact are important in the workplace, we suggest that more guest lecturers should be invited to speak to the office administration students on subjects like etiquette, common sense, and ethical practices in the workplace. The paper has demonstrated that at least two guest lecturers have commented on the issue of tardiness and etiquette in the workplace.

We are of the view that shorthand is an important skill and although the more sophisticated recording devices have somewhat rendered shorthand outdated in many workplaces, practicing shorthand demonstrates a real dedication to the craft and is useful in rural areas in the Pacific where there are no recording devices available.

Students discussed the importance of having a good command of English both written and verbal in the workplace. This is a valid point. One of the main reasons why students generally struggle with shorthand at Fiji Natiional University is their lack of command of the English language which makes it difficult to read and write in shorthand. We also argue that texting has played key role in poor grammar skills displayed by many office administration students.

Guest lectures are also important for upgrading information and skills by the appropriate people from the FNU, the employers and specialists from other training/regional organizations. Our findings have highlighted the importance of consultation, collaboration and team work in every aspect of training and employment. The future needs to be more collaboratively focused on improvement at all levels. This will require respect for the views of all concerned - employers, FNU training institutions and staff, current and past students and most certainly the public at large. A special FNU effort in obtaining information through a needs assessment should guide its development programme in all the campuses. This should focus on improvement to facilities, updating academic professional programs that will provide a 
solid foundation of basic skills and experiences and be contextually relevant with units to cover the areas in demand. Professional and technological development of FNU staff is important as it will impact positively on student learning and output and in the process satisfy the employment requirements of both the Public and Private Sectors.

\section{References}

[1] Owizy, S. (n.d.). The Relevance of Shorthand in Modern Office Operations. https://www.academia.edu/ 5579983/THE_RELEVANCE_OF_SHORTHAND_IN_MO DERN_OFFICE_OPERATIONS (Access Date: 29 December 2015)

[2] S.S. Amoor, (2008). Integrating the Internet with the Curriculum of Office Education Program in Tertiary Institutions in Nigeria. The Information Manager Vol. 8 (2) 2008 pp. 3 (Access Date: 9 January 2015)

[3] S.S. Amoor, (2009). An Evaluation of the Performance of Secretarial Students on Industrial Work Experience Scheme: A Case Study of Nigerian Universities p. 4 (Access Date: 9 January 2015) 